\title{
The Global Solar Radiation in the Southern Region of Ecuador
}

\author{
O. H. Álvarez ${ }^{1}{ }^{(0,}$, T. E. Montaño ${ }^{2}$ \\ ${ }^{1}$ National University of Loja, Project "Prometheus, Old Sages”, SENESCYT, Loja, Ecuador \\ ${ }^{2}$ Energy Area, National University of Loja, Ciudadela Guillermo Falconí Espinosa, Loja, Ecuador \\ Email: orlando21alvarez@gmail.com, thuesmon@yahoo.es
}

How to cite this paper: Álvarez, O.H. and Montaño, T.E. (2019) The Global Solar Radiation in the Southern Region of Ecuador. Open Access Library Journal, 6: e5183. https://doi.org/10.4236/oalib.1105183

Received: January 14, 2019

Accepted: February 25, 2019

Published: February 28, 2019

Copyright (c) 2019 by author(s) and Open Access Library Inc.

This work is licensed under the Creative Commons Attribution International License (CC BY 4.0).

http://creativecommons.org/licenses/by/4.0/

\begin{abstract}
In this work an approach to the theoretical solar radiation in the South Region of Ecuador is presented, using the Hottel Model ([1] [2]), considering the cloudiness and the topography Shadows. The maps of Global Solar Radiation are shown for the months of January, August and Annual one, considering the heights over the middle sea level extracted of the Digital Elevation Model. This work will allow specialists and engineers to know the most favorable areas for the location of photovoltaic or photothermic plants in the southern region of Ecuador. The effects have been analyzed by the orography and the methods used were discussed. The role of the orography is analyzed to improve the values' product of the modeling of the solar radiation. Conclusions and recommendations are given.
\end{abstract}

\section{Subject Areas \\ Aerography, Atmospheric Sciences}

\section{Keywords}

Hottel Model, Solar Radiation, Orographic Shadows

\section{Introduction}

The present work is part of the hypothesis of that it is possible to obtain maps of radiation from theoretical models that are consistent with the reality, and the objective is the preparation of maps of global radiation that allow their use to know with greater precision solar energy potentials in the Southern Region of Ecuador (RSE), as for the determination of different environmental components, such as potential evapotranspiration [2].

The work focused on obtaining the values of direct, diffuse and global radia- 
tion on a horizontal surface, considering a clear sky, using the "Hottel model" [1] [3]. From data on reanalysis of the amount of daytime clouding [4], the monthly maps are corrected, as well as the annual average global radiation map. Finally, results are improved using the analysis of the brilliance maps obtained from the digital altitude model for RSE.

It is known that the atmosphere exerts a redistribution effect of the radiation that receives from the sun, for example, on a very clear day; a relatively small part becomes diffuse radiation, whereas most of it remains as direct. On the other hand, on a cloudy day, the redistribution of radiation is much more noticeable. Dense clouds have a very high albedo (reflected energy fraction), which makes a large part of the solar radiation reflected in the outer space on a densely cloudy day. In addition, the energy that manages to pass through the clouds is only diffuse radiation.

According to recent developments in the calibration of radiometric broadband, solar instrumentation and improvements in the accuracy of the measurements are profiled in relation to the diffuse radiation and the calibration of radiometers [2]. Several models of estimation of the broadband solar radiation include some developed in the National Renewable Energy Laboratory of the United States, for the estimation of the direct, total, hemispheric and present diffuse radiation; at the moment, uncertainties are representative in the measured data [2].

Errors between 25 and $100 \mathrm{w} / \mathrm{m}^{2}$ are possible in the pirheliometric data and errors of $25 \mathrm{w} / \mathrm{m}^{2}$ in the Pirihelio Métricos data can occur under clear sky conditions. These instrumental errors are important if it is modeling instant profiles, schedules, subtimes, or diaries. Analyses of annual totals of corrected and uncorrected data have shown differences of less than $0.1 \%$ in the outcome [5].

On the other hand, a reflectance map can be based on experimental data. It can mount the sample of a surface and measure its apparent brightness from a fixed display point under fixed lighting conditions, while its orientation varies. Similarly, it can take a box from a test object in a known way and calculate the orientation of the corresponding surface element for each point in the image. The reflectance map is then obtained by reading the brightness measurements at each point [6] [7] [8] [9].

Alternatively, it can even use more detailed information about light reflection from the surface. The bidirectional Reflectance distribution function (BRDF) describes how bright a view surface can appear from a specific address when it is illuminated from another direction fixed with Advance. Through integration on a given distribution of light sources, the reflectance map can be calculated from this information.

Then, a reflectance map is similar to a "convolution" of the BRDF and the distribution of the radiation source. More commonly, reflectance maps are based on phenomenological models rather than physical reality. The so-called "Lambertianas surfaces", or the perfect diffuser, for example, have the property of ap- 
pearing equally bright from all directions from where it is observed.

In the same way they reflect all the light without absorbing anything. In fact, these two conditions are sufficient to determine in a unique way the BRDF of such a surface, and from this the reflectance map, providing the positions of the given light sources. Some reflectance maps are based on mathematical models of the interaction of light with the surface. These models tend to be very complex to obtain an analytical solution or very simple to represent effectively the real surfaces. However, some have come very close to the prediction of observed behavior of particular surfaces.

New reflectance maps were determined based on methods to produce maps of shaded reliefs that do not depend on the comprehension of the process of formation of the images or the physics of the reflection of light, but of the way in which the light at one point depends on the gradient of the underlying geographical surface.

Because reflectance maps provide apparent brilliance as a function only of a local surface gradient, it does not take into account the effects dependent on the position of the surface element. One of these effects is the illumination of one surface element on the other. Fortunately, this mutual lighting effect is small unless the surface reflectance is very high.

Another position-dependent effect on the apparent brightness is blocking the light by a portion of the surface before the light reaches another.

Likewise the scattering of light by the molecules of air and aerosols changes the apparent brilliance of an element of surface seen through the atmosphere. However, the difference between brilliance and the value of the environment decreases with the thickness of the gaseous layer through which the surface is visualized [10] [11] [12] [13].

\section{Materials and Methods}

For the realization of this work, initially, the preparation of an Excel book was started using the methodology proposed by Passamai (2000) [1], adding a group of spreadsheets, in such a way that the abstract could be obtained automatically. Monthly and yearly of the daily values for the selected geographical points [14] are able to interpolate these summaries later in the preparation of the different maps for the study area.

Later and due to the need to know the behavior of solar radiation, and to determine also, which sectors of the southern region of Ecuador and at what moment of the year, have the greatest solar potential, and considering the absence of sufficient series of observations of this meteorological variable, were used the theoretical methods of Hottel and PVGIS for the calculation of the variable, which are presented in the work of Molina and others [15] in the form of a software, based on LABVIEW that offers a graphical programming approach that helps to visualize every aspect of the application, including hardware configuration, measurement data, and debugging. This visualization makes it simple to integrate measurement hardware from any vendor, represent complex logic on the 
diagram, develop data analysis algorithms, and design custom engineering user interfaces., for use by any interested in knowing the timetable, daily, monthly and annual values of the global radiation in the southern region of Ecuador.

The model of Hottel [1] is of the form:

$$
\tau_{b}=a_{0}+a_{1} \cdot \mathrm{e}^{\left(-k / \cos \left(\theta_{z}\right)\right)}
$$

Here $a_{0}, a_{1}$ and $k$ are parameters adjusted empirically, used by [8] and Álvarez and others [15].

$$
\begin{aligned}
\theta_{z}= & a \cos (\sin (\text { radianes }(\lambda))) \times \sin (\text { radianes }(\delta)) \\
& +\cos (\text { radianes }(\lambda)) \times \cos (\text { radianes }(\delta)) \times \cos (\omega)
\end{aligned}
$$

where:

$$
\begin{aligned}
& \lambda=\text { Latitude; } \\
& \delta=\text { Declination of the Sun; } \\
& \omega=(-0.261799 \times(\text { HS- } 12)) \times 360 / 2 \pi ; \\
& \text { HS = Solar Time. }
\end{aligned}
$$

For estimating irradiation or diffuse irradiance $\tau_{d}$ for a horizontal surface is used the expression of Liu and Jordan [9] of the form:

$$
\tau_{d}=0.2710-0.2939 \tau_{b}
$$

where $\tau_{d}$ and $\tau_{b}$ are adimensional.

By integrating these equations, from the sunrise to the sunset, it can get irradiation over a day. In the Hottel model, the standard atmosphere represents a typical average latitude and pollution-free condition, independent of the thickness of the ozone.

Elevation data obtained from the digitized topographic map of the entire southern region of Ecuador were used, with corresponding level curves from the information pertaining to the Radar Topography Mision (SRTM) [16] of the National Aeronautics and Space Administration (NASA) (cells every 90 meters) which was cut and the information of longitude, latitude and height were introduced in the CAD surfer, obtaining a numerical model of altitude (MNA) by means of interpolation, using a model Krigging lineal Simple, every $0.001^{\circ}$ of longitude and latitude, which allows to obtain the value corresponding to the maximum height at each point (Figure 1).

The geographical points were selected from the values of longitude and geographic latitude and the height on the middle sea level obtained from the numerical model of altitude for the project zone, calculated the time values of direct, diffuse and global radiation for each point and subsequently, the corresponding global radiation maps were made, for each month and for the yearly.

Once the corresponding maps were obtained, we proceeded to rectify those using data for reanalysis of the daytime clouding values, recalculating the maps. From the monthly and annual values of global radiation, on a horizontal surface, considering the condition of clear day, for the different months, as well as the annual average, obtained by applying corrections due to the cloudiness, obtained 


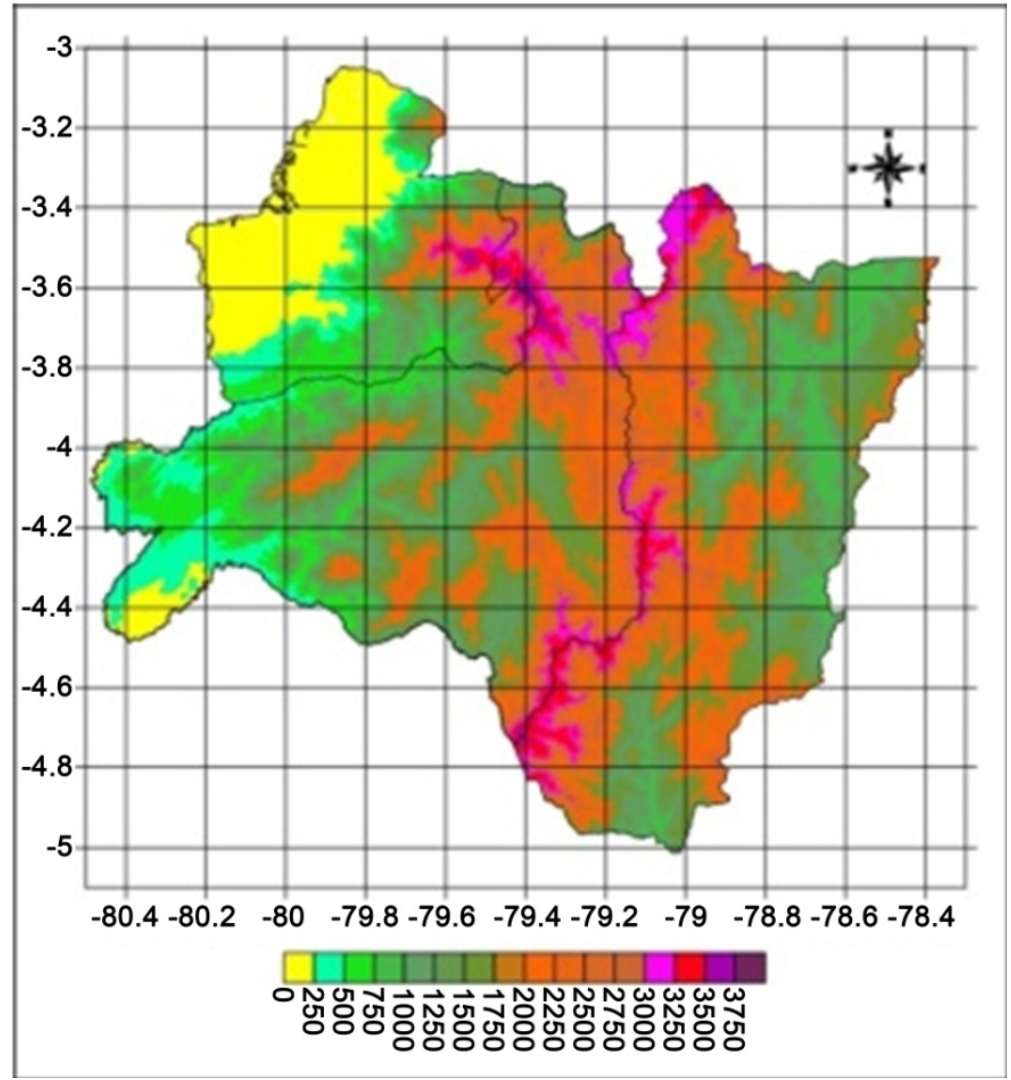

Figure 1. Numerical model of altitude (MNA) of the provinces El Oro, Loja and Zamora Chinchipe, Ecuador.

from the reanalysis carried out by NASA, the values of the global radiation are obtained for the months and for the annual average [4].

Reanalysis data were obtained from the NASA website: Surface Meteorology and Solar Energy [4]. https://eosweb.larc.nasa.gov/cgi-bin/sse/sse.cgi?+s01\#s01 https://eosweb.larc.nasa.gov/cgibin/sse/grid.cgi?\&num

From the data of the tables obtained for each one of the points of a grid with the ends: $-77.0^{\circ} \mathrm{W},-81.0^{\circ} \mathrm{W}$; and $-3.0^{\circ} \mathrm{S},-6.0^{\circ} \mathrm{S}$, longitude and latitude respectively, with a cell size of $0.001^{\circ}$, the average monthly and annual values were calculated for the period of 22 years included in the reanalysis, by means of an interpolation using a linear Krigging model.

We worked on the Software Envi 4.7, where we used the topographical modeling on data of the numerical model of altitude (MNA) obtained from the data SRTM and the Geological Service of the United States (USGS) [17] and other digital data of elevation to generate Lambertianas surfaces (shaded relief), as well as to extract parametric information, including slope, appearance and different convection and curvatures. All parameters are calculated by fixing a quadratic surface to the digital elevation data for the total size of the Kernel and obtaining the appropriate derivatives. It can be change the size of the Kernel so that Multiscale topographic information can be extracted.

When the color of a pixel (digital unit of an image) based on their neighbors, 
it is talking about a window or Kernel (usually a $3 \times 3$ or $5 \times 5$ grid); Which is nothing more than a convolution matrix that indicates which pixels should influence the original pixel and how much. A weight is made for each pixel covered by the specified Kernel. This is the basis for many filtering algorithms [18]. http://antongerdelan.net/opengl/kernels.html

On the other hand, the possibilities offered by the ENVI geographic Information system for topographical modeling are used to obtain brilliant or shaded embossing maps. The following Figure 2 shows examples of how the ENVI 4.7 works.

In order to compare the results, data from NASA's reanalysis for insolation were obtained, which are shown in Figure 3 after being transformed to the same

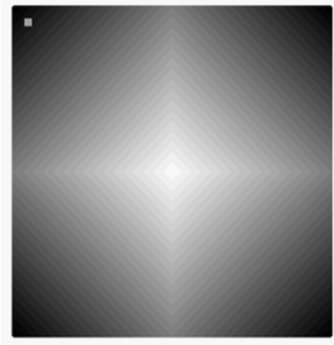

Aspect Image

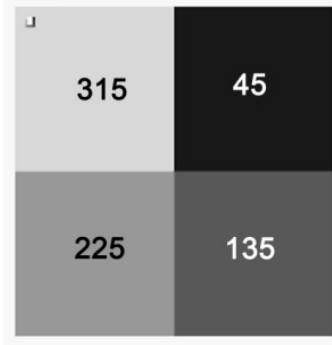

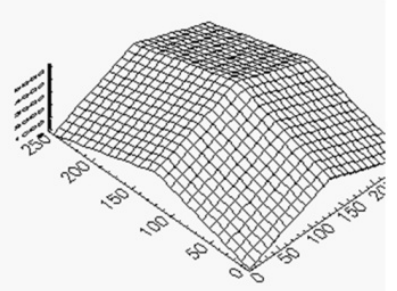

Shaded Relief (Lambertian)

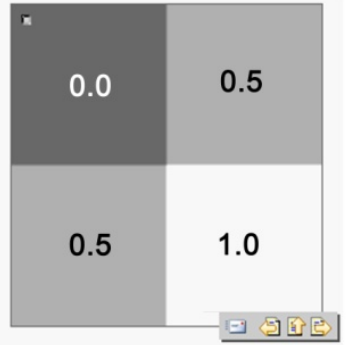

Figure 2. Examples of topographic modeling outputs in Envi 4.7.

\begin{tabular}{|c|c|c|c|c|c|c|c|c|}
\hline & G14 & $\checkmark$ & $f_{x}$ & IS(KWHN & Is]INS(KI & 12)'!G14/ & $778 * 31$ & \\
\hline 4 & A & B & $C$ & D & $E$ & $F$ & G & $\mathrm{H}$ \\
\hline 1 & LAT & LONG & 1 & II & III & IV & v & VI \\
\hline 2 & -5 & -81 & 834.76 & 752.97 & 843.69 & 768.95 & 732.09 & 683.63 \\
\hline 3 & -4 & -81 & 816.91 & 743.90 & 830.30 & 773.27 & 741.02 & 690.11 \\
\hline 4 & -3 & -81 & 796.82 & 734.83 & 828.07 & 778.67 & 748.83 & 699.83 \\
\hline 5 & -2 & -81 & 786.77 & 728.78 & 831.41 & 782.99 & 756.64 & 701.99 \\
\hline 6 & -1 & -81 & 780.08 & 722.73 & 829.18 & 778.67 & 763.34 & 711.71 \\
\hline 7 & 0 & -81 & 761.11 & 716.68 & 819.14 & 779.75 & 764.45 & 713.87 \\
\hline 8 & -5 & -80 & 828.07 & 748.94 & 844.81 & 765.71 & 732.09 & 683.63 \\
\hline 9 & -4 & -80 & 813.56 & 739.87 & 836.99 & 768.95 & 741.02 & 692.27 \\
\hline 10 & -3 & -80 & 800.17 & 734.83 & 828.07 & 774.35 & 748.83 & 700.91 \\
\hline 11 & -2 & -80 & 786.77 & 727.77 & 832.53 & 779.75 & 754.41 & 701.99 \\
\hline 12 & -1 & -80 & 774.50 & 724.75 & 828.07 & 772.19 & 761.11 & 711.71 \\
\hline 13 & 0 & -80 & 758.87 & 715.67 & 821.37 & 775.43 & 756.64 & 709.55 \\
\hline 14 & -5 & -79 & 823.60 & 760.03 & 843.69 & 763.55 & 732.09 & 680.39 \\
\hline 15 & -4 & -79 & 799.05 & 748.94 & 835.88 & 766.79 & 741.02 & 692.27 \\
\hline 16 & -3 & -79 & 797.93 & 736.84 & 831.41 & 771.11 & 746.60 & 700.91 \\
\hline 17 & -2 & -79 & 774.50 & 727.77 & 831.41 & 775.43 & 752.18 & 704.15 \\
\hline 18 & -1 & -79 & 770.03 & 714.67 & 822.49 & 775.43 & 758.87 & 709.55 \\
\hline
\end{tabular}

Figure 3. Example of data result of the reanalysis of insolation $\left(\mathrm{MJ} / \mathrm{m}^{2}\right)$. 
units, from which the corresponding maps were made. An overlay was made for the data of the monthly sum of the theoretical radiation obtained by the Hottel method for each particular month and for the annual average, by means of multiplication with the percent of sun hours obtained for each month and annual average to determine the quantity of radiation corresponding to each of the periods.

The shading maps obtained from the Digital elevation model were used, considering the following combinations of elevation angles and azimuth: (15.45); (15.135); (15.225); (15.315); (30.45); (30.135); (30.225); (30.315); (45.45); (45.135); (45.225); (45.315); (60.45); (60.135); (60.225); (60.315). From these maps were made the average maps according to the azimuth North and South and finally were averaged to obtain the map of shadows for the entire project area.

Once the shadow map was obtained, the maps of global solar radiation were multiplied for months and yearly considering the hours of sunshine for each period by the shadow map for the area. A comparison was made of the maps with respect to the maps obtained from the reanalysis of NASA's insolation [4]. In the same way an analysis of the results obtained with the maps obtained by the CONELEC [18] for all Ecuador is made, starting from the model.

\section{Results and Discussion}

Figures 4-6 show the maps of the sum of the solar radiation in clear days corresponding to the months of January, August and the annual average in the study area.

Figures 7-9 show the maps of the months of January, August and annual average percent of the hours without clouding obtained from NASA reanalysis [4] and subsequently processed for the project area.

Daily average value maps for months considering percent of clear days per month for January, August and the annual period are shown in Figures 10-12.

It is observed, that due to the presence of the cloudiness, considerably decrease the values of solar radiation possible to obtain according to the model of clear day of Hottel, in addition the zones with greater and lower values of this meteorological factor are inverted, due to the cloudiness generated in the highest areas of the Andean cordillera.

When comparing the result of annual irradiation with NASA's irradiation values considering the annual frequency of sunny days, it can be observed that there are no major differences (Figure 13). The map of the differences is shown in Figure 14.

Multiplications of the maps of each month and yearly were carried out by the shaded relief map (Figure 15) in order to obtain the final resulting maps. The maps of the months of January (Figure 16) and August (Figure 17) and the yearly (Figure 18) are compared with the maps obtained by the National Electricity Council of Ecuador [19]. Schematics are shown for the January maps (Figure 19), August (Figure 20) and annual (Figure 21), which are consistent with the maps obtained in this work after being converted to the same units used 


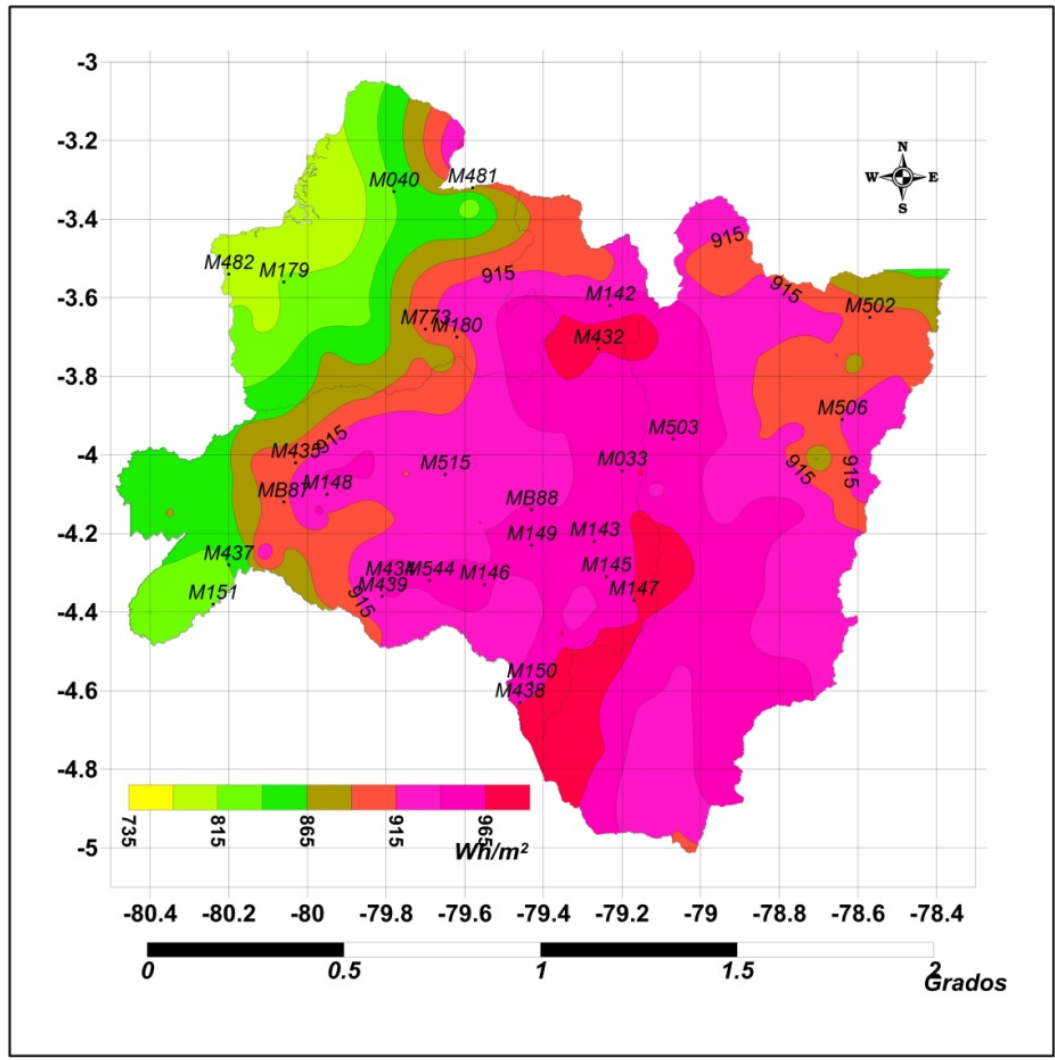

Figure 4. Mean of global radiation in clear days, in January.

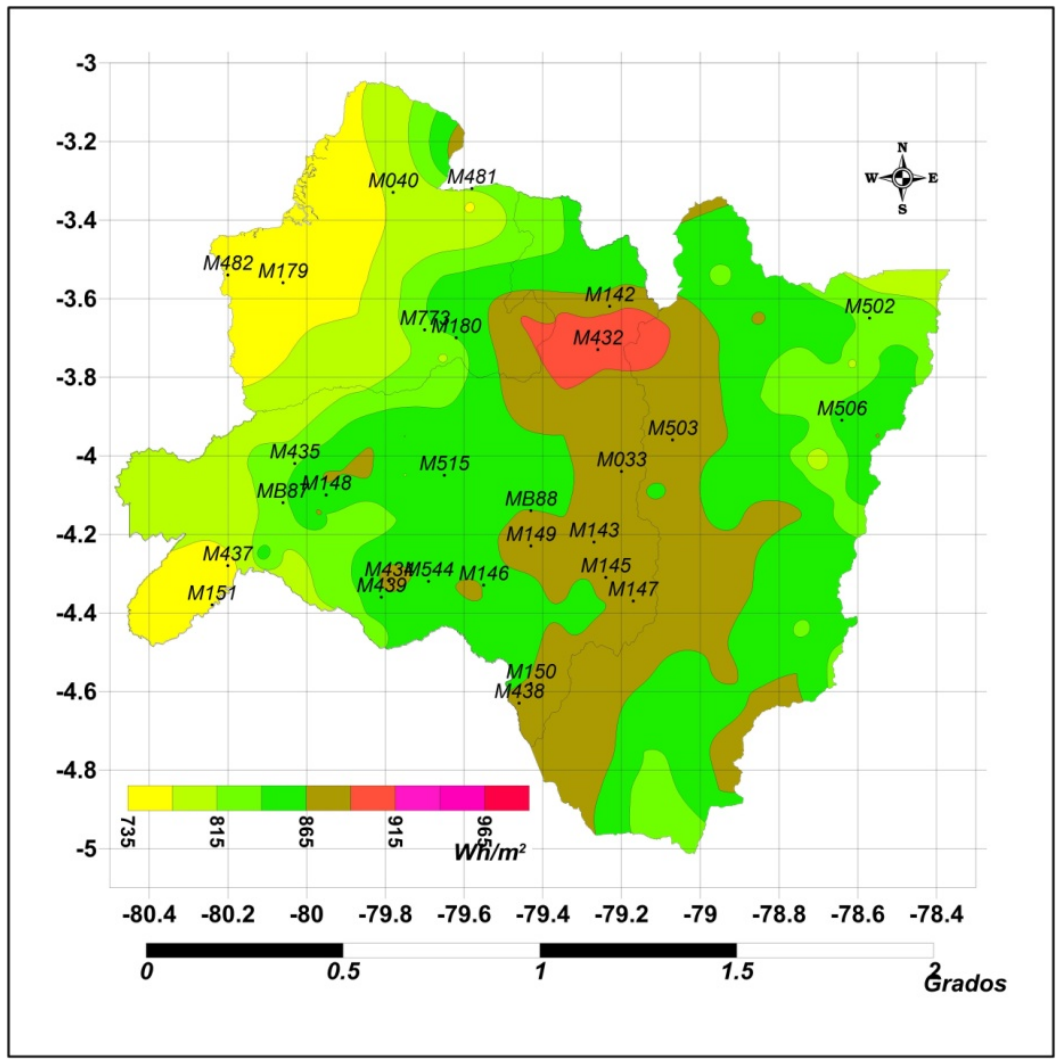

Figure 5. Mean of global radiation in clear days, in August. 


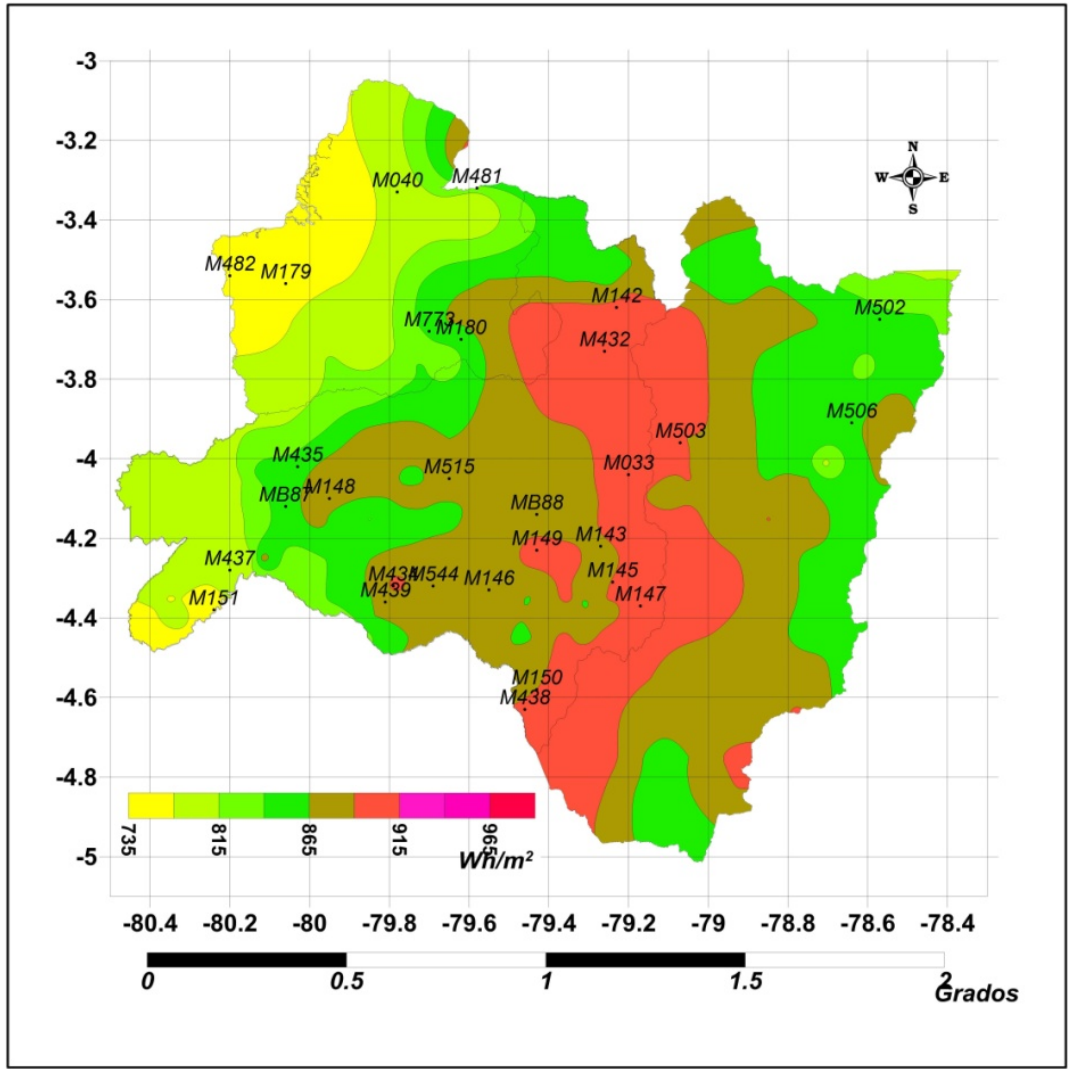

Figure 6. Mean of global radiation in clear days, in anual.

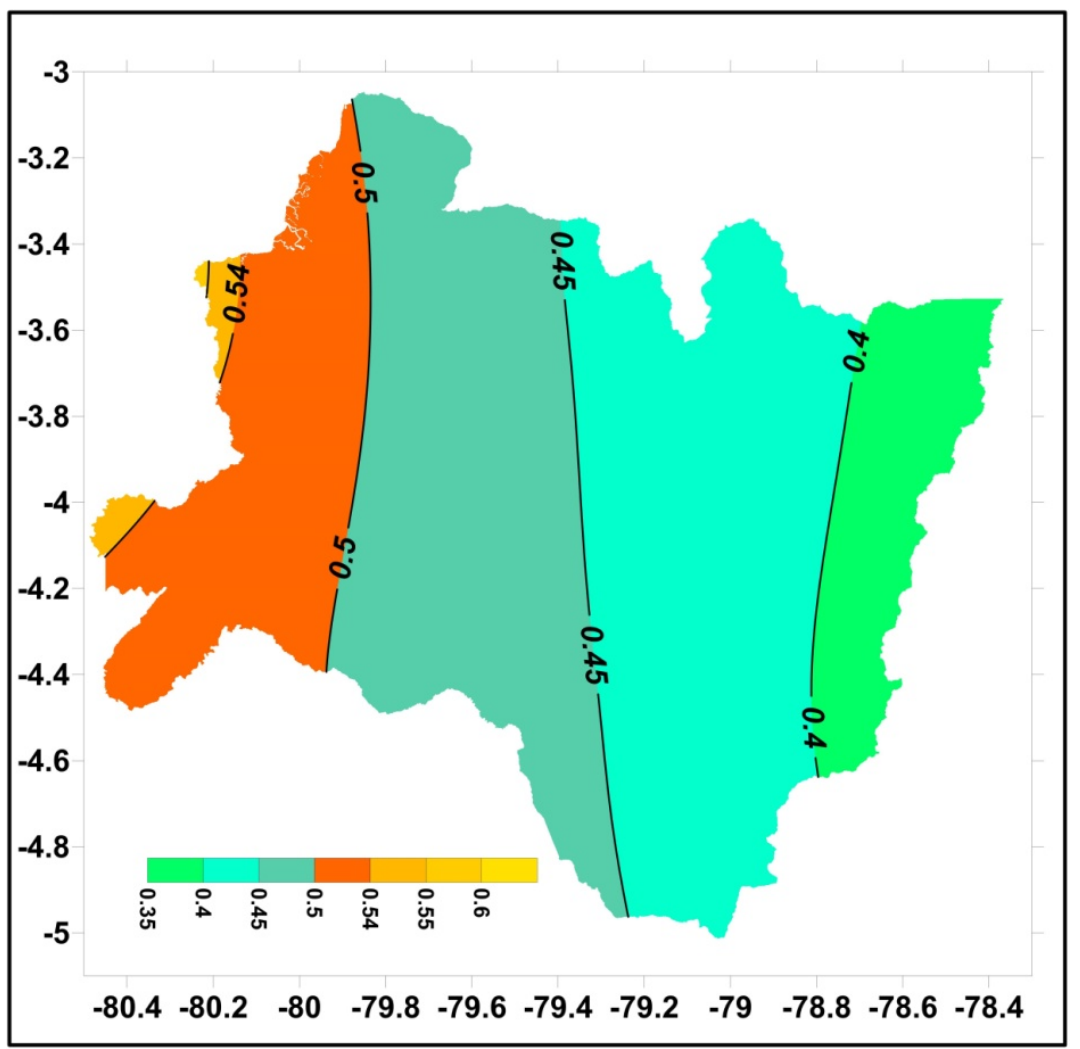

Figure 7. Sun hours (\%). Average January. 


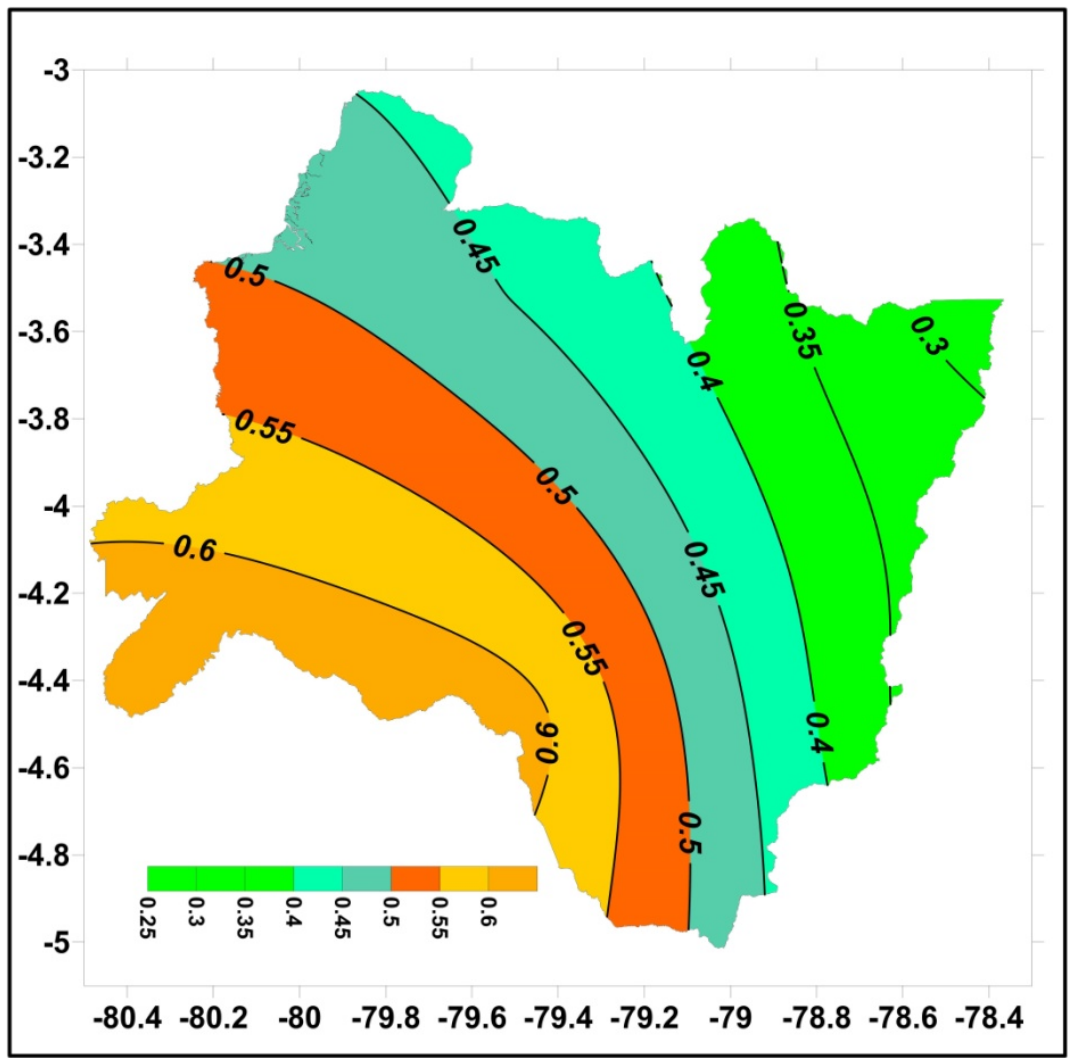

Figure 8. Sun hours (\%). Average August.

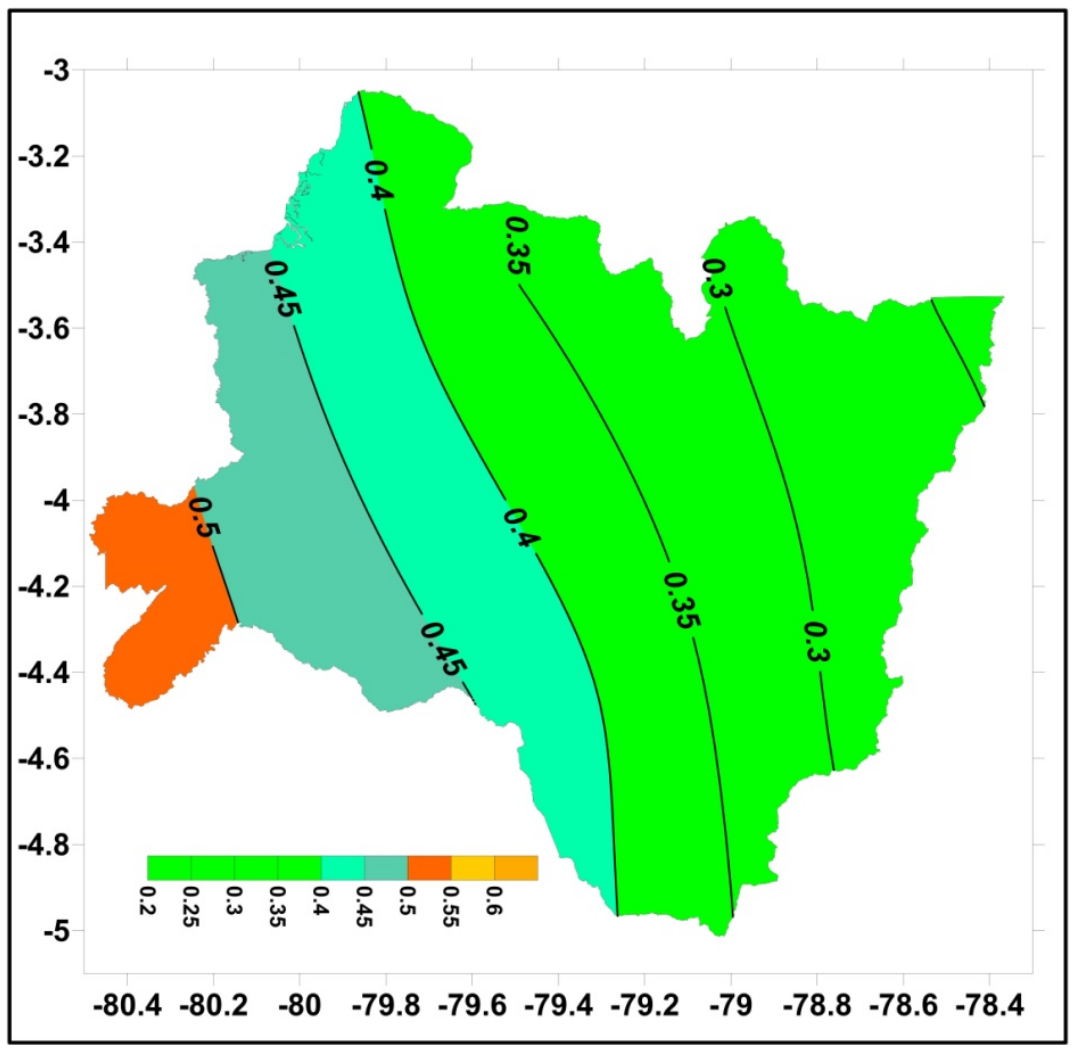

Figure 9. Sun hours (\%). Average Anual. 


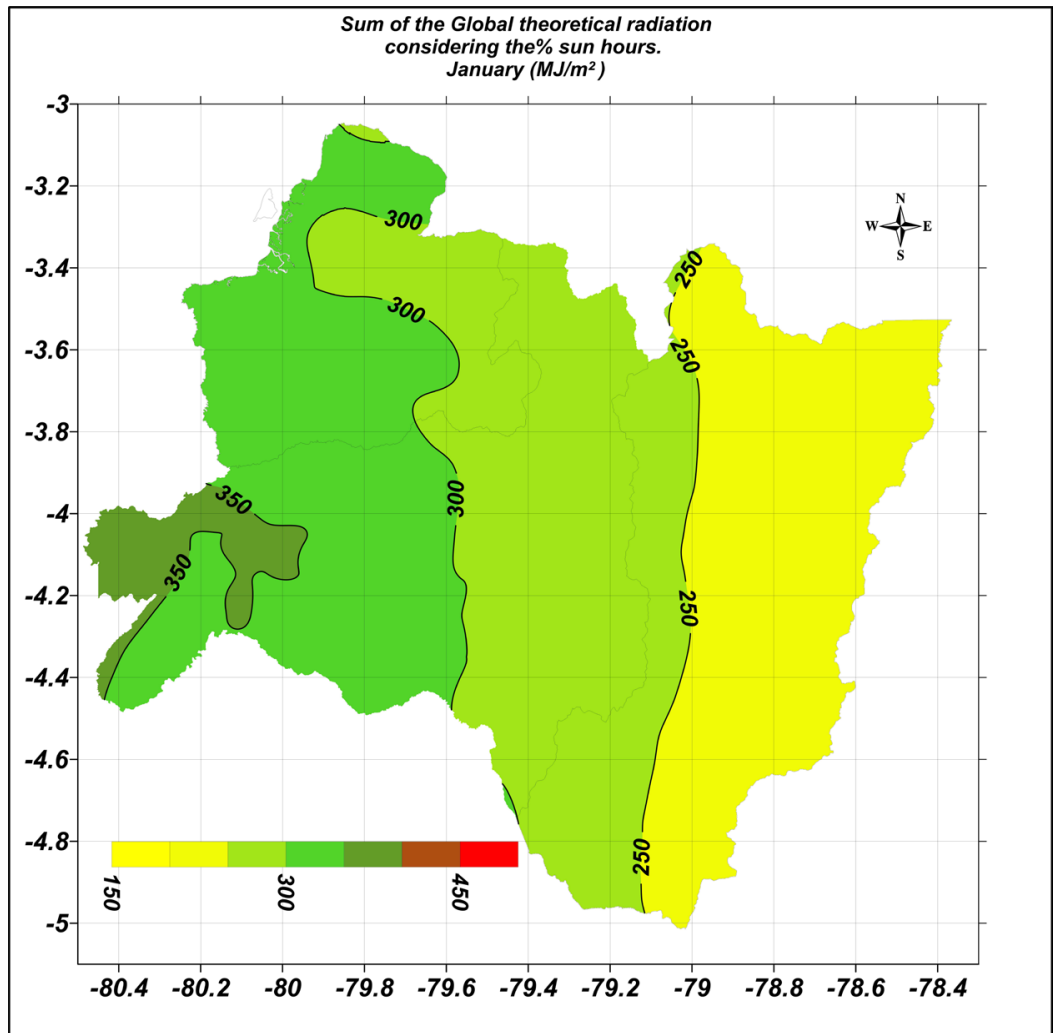

Figure 10. Mean of global radiation, in January.

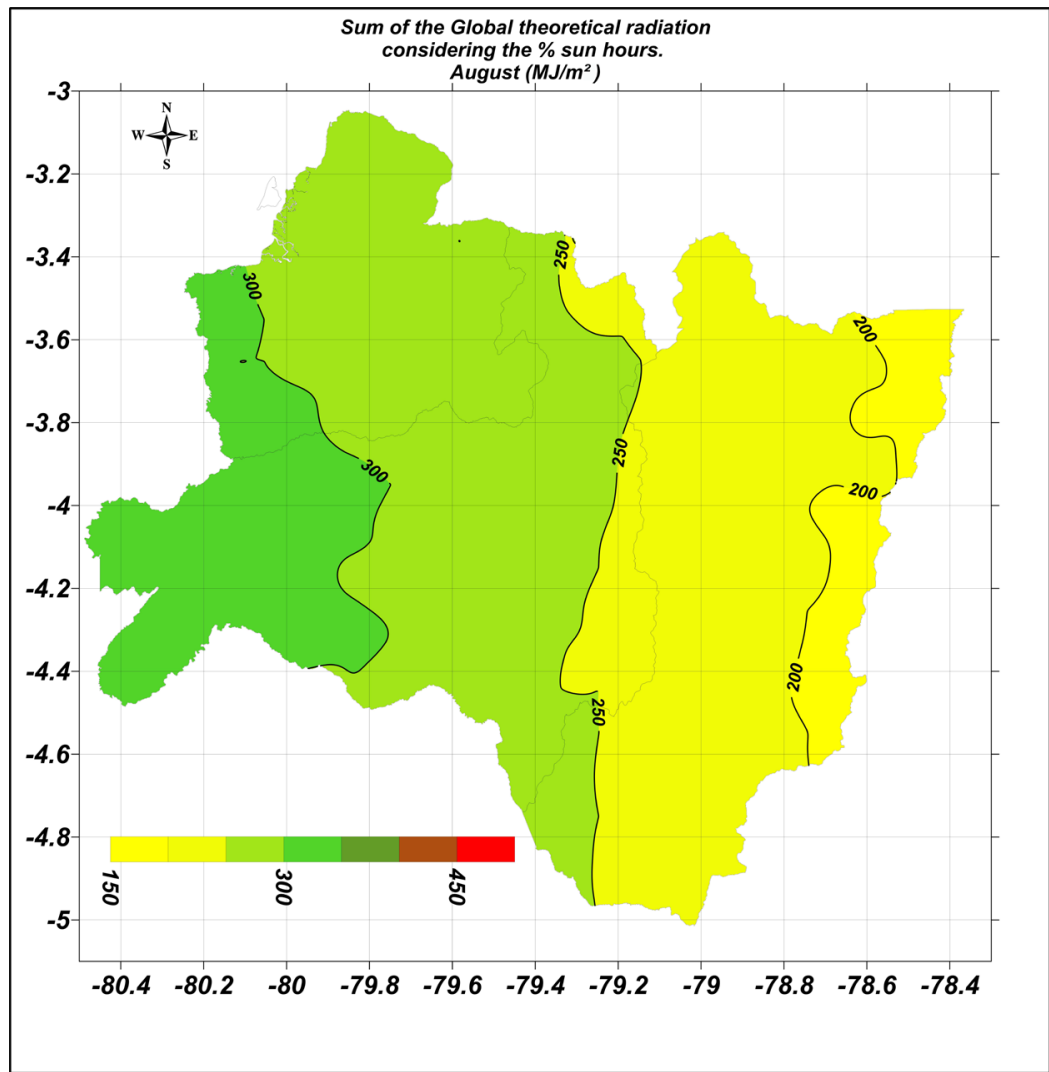

Figure 11. Mean of global radiation, in August. 


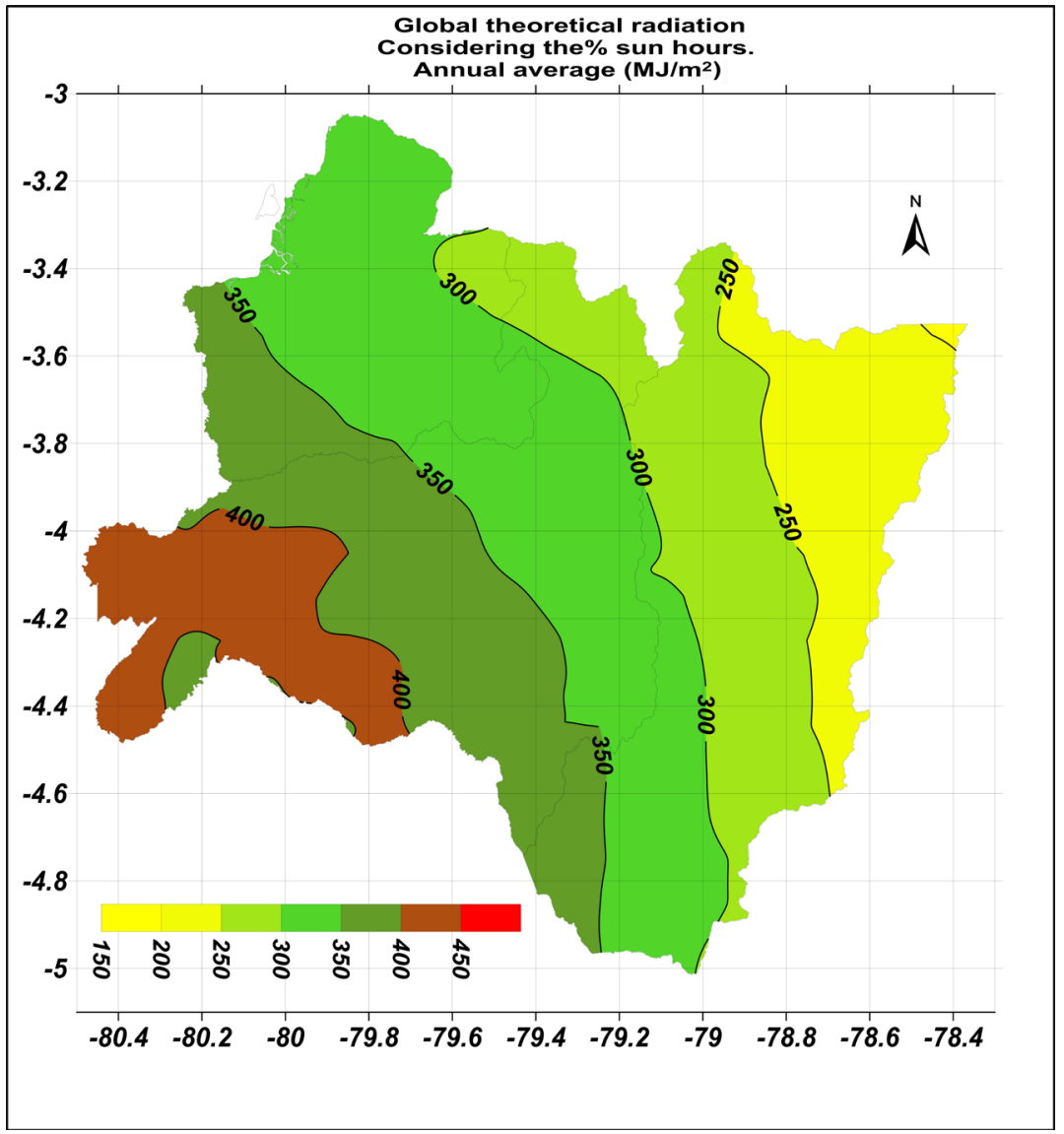

Figure 12. Mean of global radiation, annual.

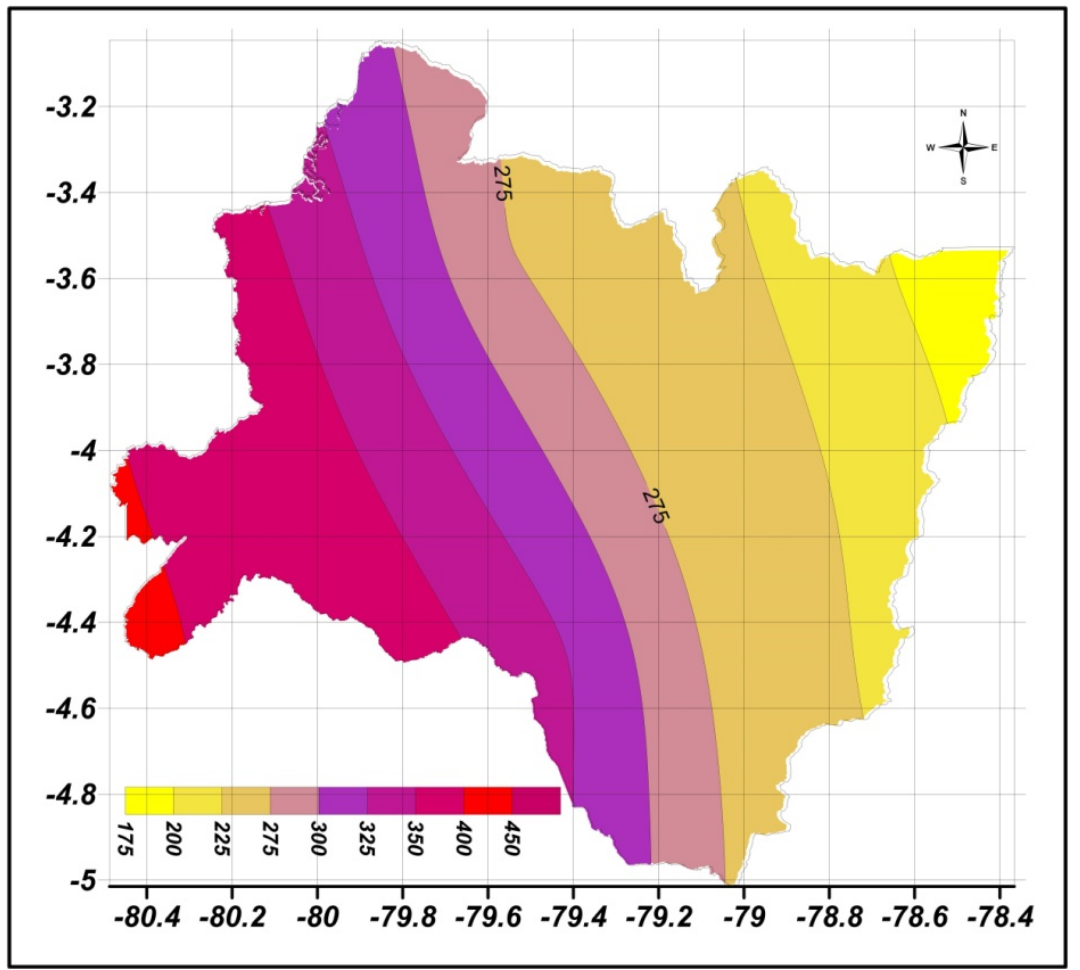

Figure 13. Global radiation, annual average. According to NASA data [4]. 


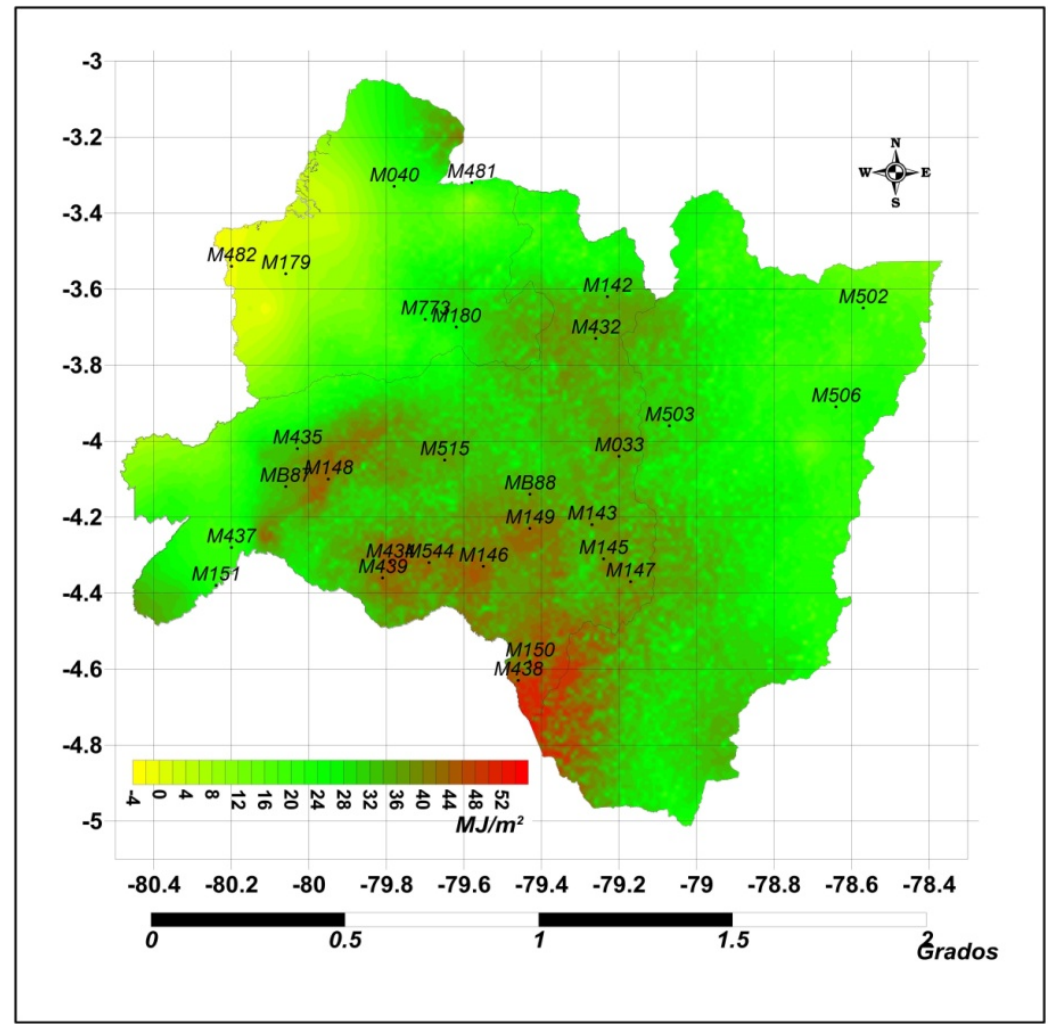

Figure 14. Global radiation differences, annual average.

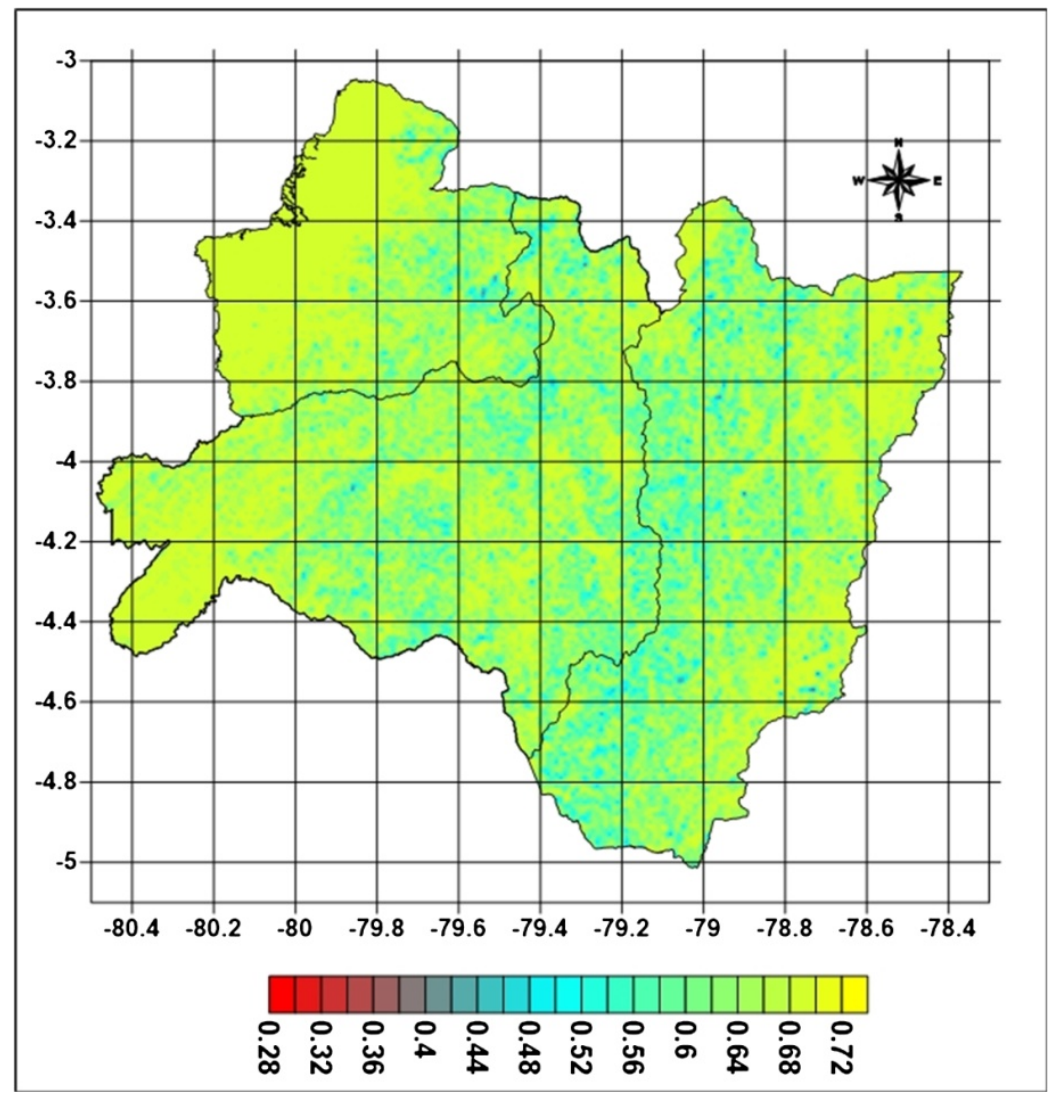

Figure 15. Shaded relief map of the RSE. 


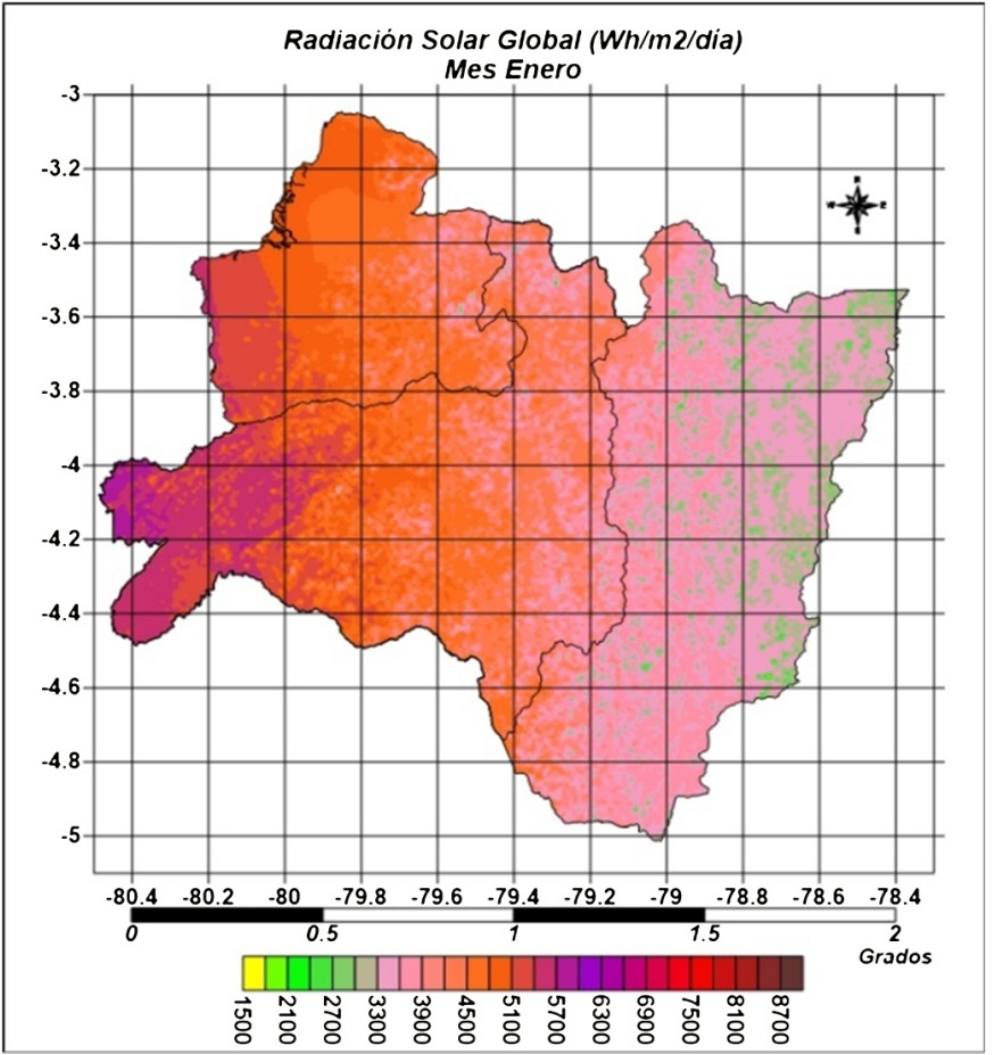

Figure 16. Global solar radiation in January.

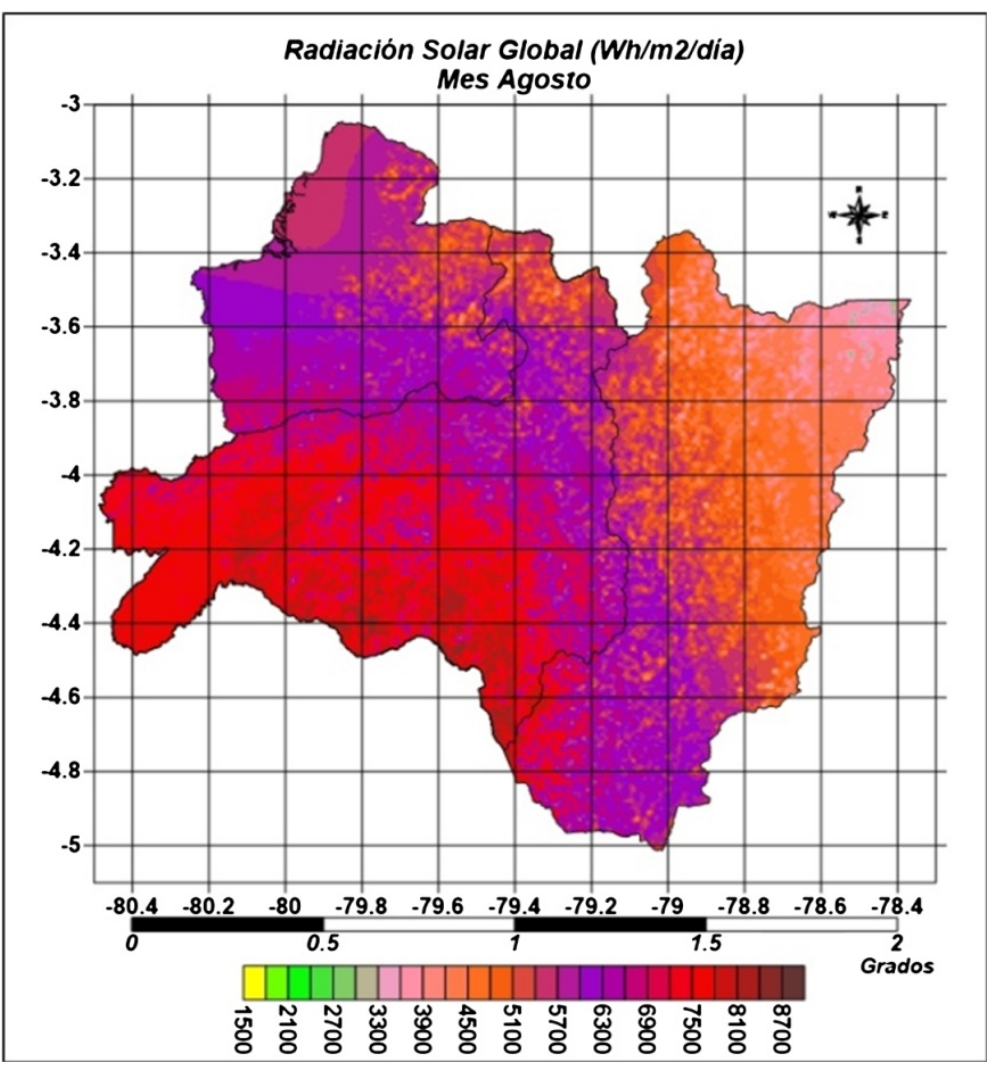

Figure 17. Global solar radiation, in August. 


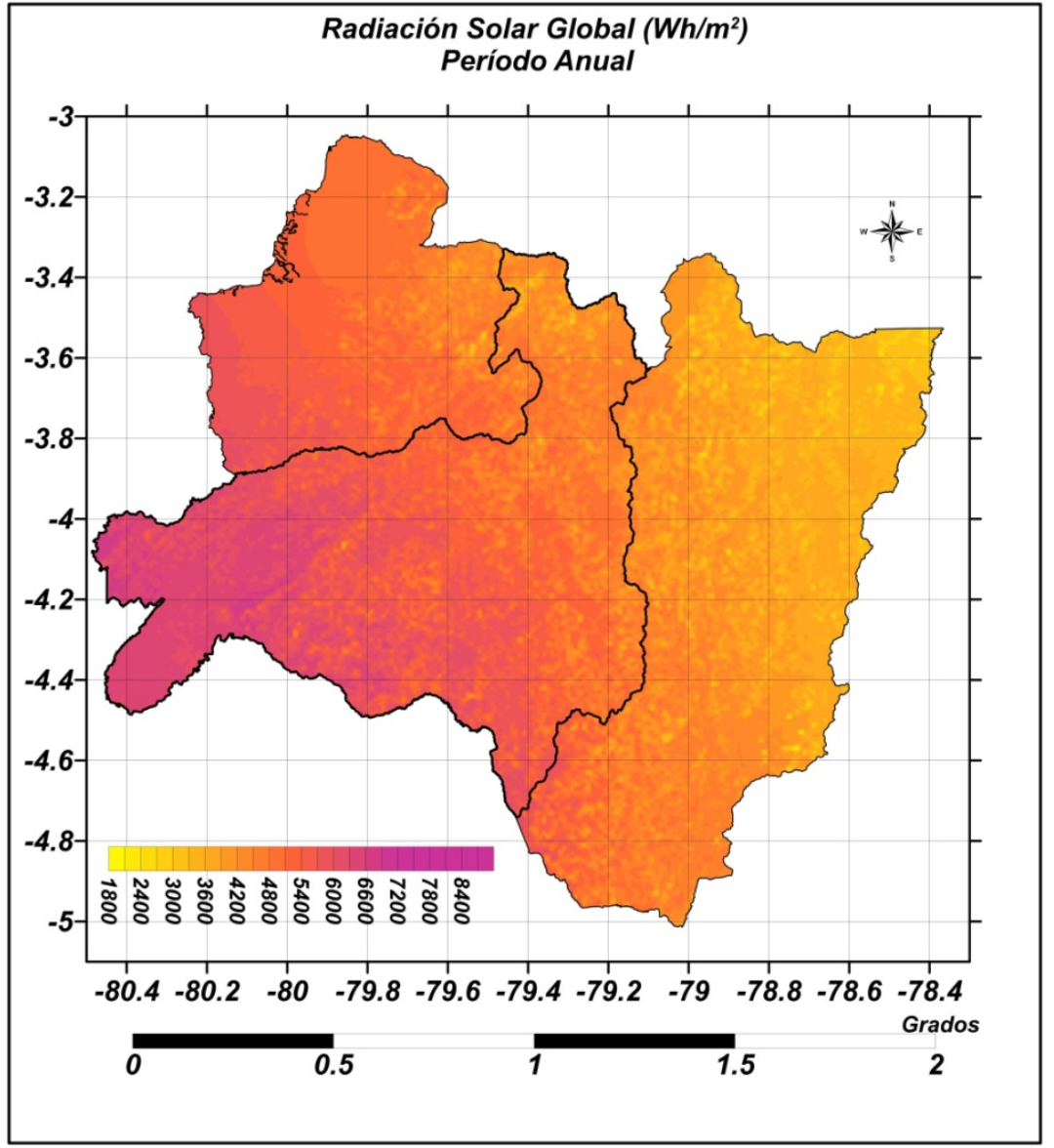

Figure 18. Global solar radiation, in annual.

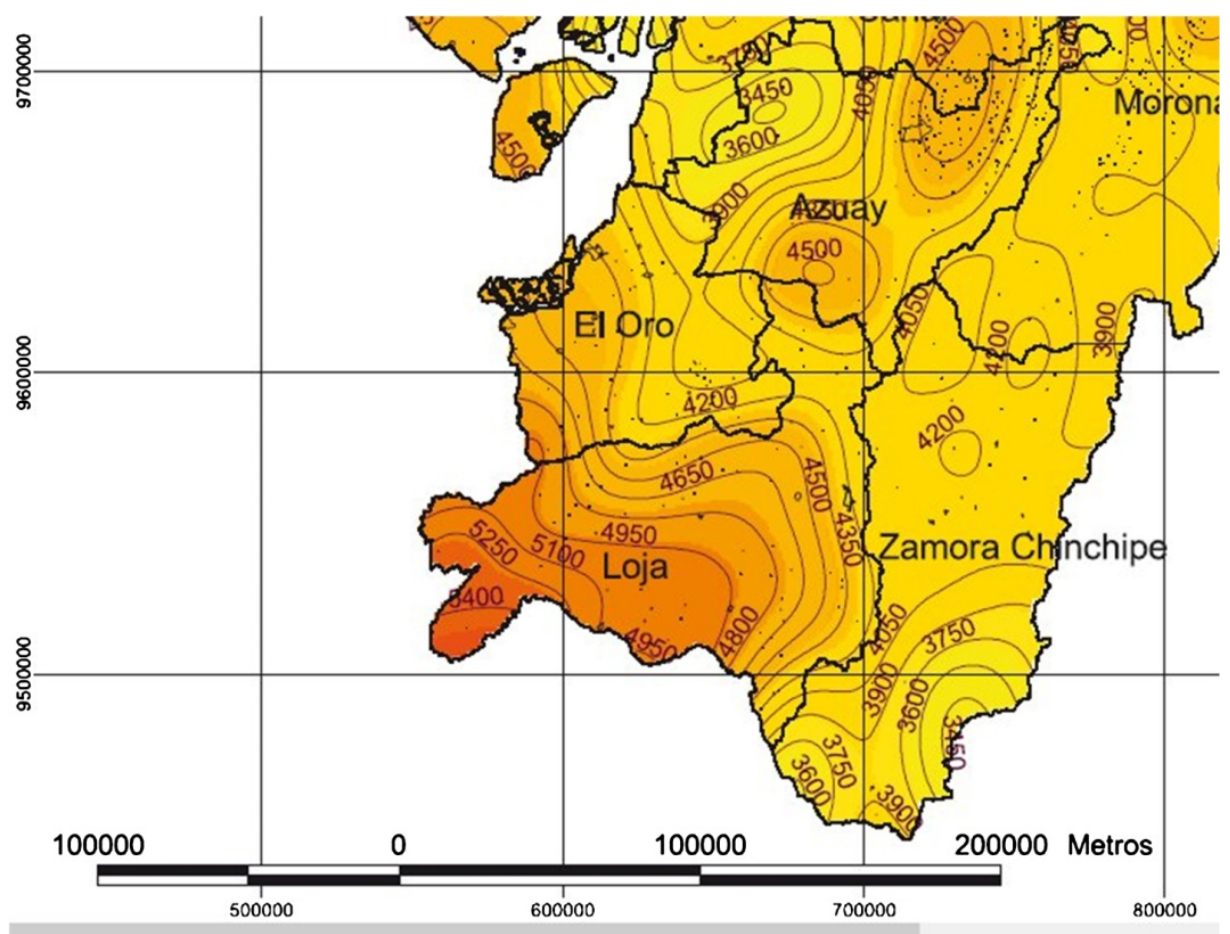

Figure 19. Outline of the map of the month of January. CONELEC [18]. 


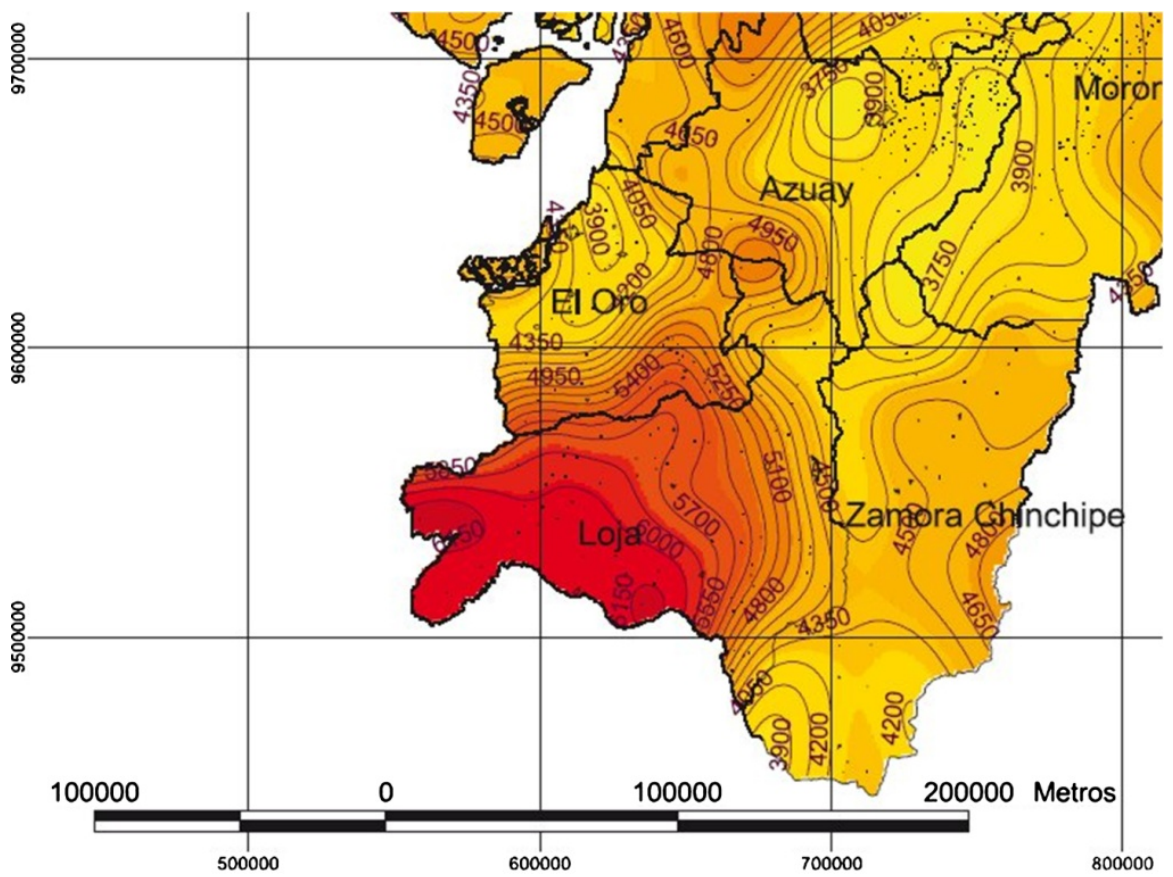

Figure 20. Outline of the map of the month of August. CONELEC [18].

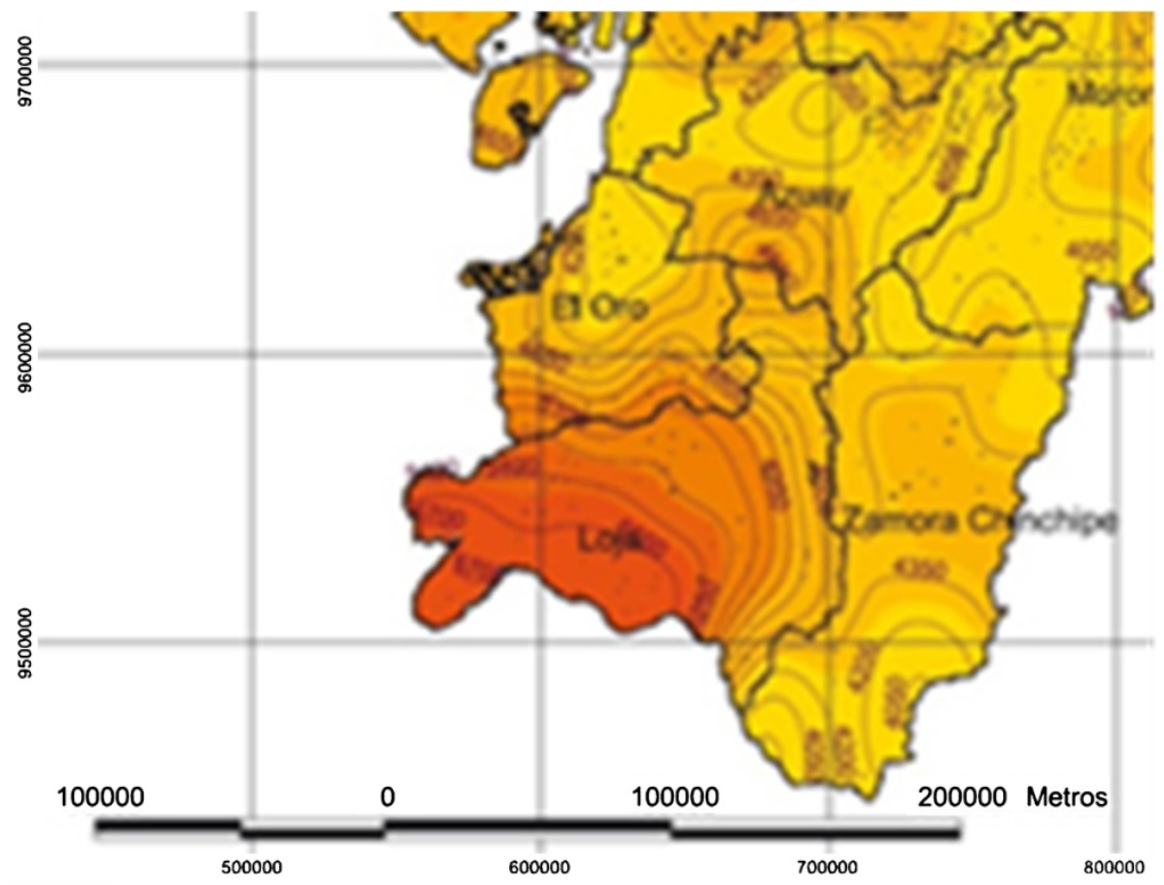

Figure 21. Outline of the annual map. CONELEC [18].

by CONELEC [18].

\section{Conclusions}

The maximum values of global radiation, considering the days with clear skies, are to the west of the project area while the minimums appear, mainly to the east of it, coinciding with the zones of higher percent monthly of clear days and 
cloudy days respectively.

There are no significant differences between the annual values obtained and those reported in the NASA reanalysis [4], as well as those obtained by the CONELEC [19].

By applying the slope and orientation of the slopes to the present model, the shaded relief map has obtained a more representative model of the average global radiation to be obtained in the southern region of Ecuador.

\section{Acknowledgements}

This scientific work has been financed by the Prometheus Project of the National Secretariat of Science, Technology and Innovation (Ecuador).

\section{Conflicts of Interest}

The authors declare no conflicts of interest regarding the publication of this paper.

\section{References}

[1] Passamai, V.J. (2000) Determinación de radiación solar horaria para días claros mediante planilla de cálculo. Avances en Energías Renovables y Medio Ambiente. http://www.unsa.edu.ar/ passamai/passam2.pdf

[2] Myers, D.R. (2003) Solar Radiation Modeling and Measurements for Renewable Energy Applications: Data and Model Quality. International Expert Conference on Mathematical Modeling of Solar Radiation and Daylight-Challenges for the 21 st Century Edinburgh, Scotland, 15-16 September 2003, 15 p.

[3] Hottel, H.C. (1976) A Simple Model for Estimating the Transmittance of Direct Solar Radiation through Clear Atmospheres. Solar Energy, 18, 129. https://doi.org/10.1016/0038-092X(76)90045-1

[4] NASA (2013) Surface Meteorology and Solar Energy. https://eosweb.larc.nasa.gov/cgibin/sse/sse.cgi?+s01\#s01 https://eosweb.larc.nasa.gov/cgi-bin/sse/grid.cgi?\&num

[5] Wilcox, S., Bin Mahfoodh, M., Al-Abbadi, N., Alawaji, S. and Myers, D. (2001) Improving Global Solar Radiation Measurements Using Zenith Angle Dependent Calibration Factors. In Forum 2001 Solar Energy, The Power to Choose. American Solar Energy Society, Washington DC.

[6] Gopinathan, K. and Soler, A. (1995) Diffuse Radiation Models and Monthly-Average, Daily, Diffuse Data for a Wide Latitude Range. Energy, 20, 657-667. https://doi.org/10.1016/0360-5442(95)00004-Z

[7] Guevara Vásquez, S. (2003) Estimación de la Radiación Solar. UNATSABAR, Lima.

[8] Gueymard, C.A. (2014) Progress in Direct Irradiance Modeling and Validation. Proceedings of ASES Annual Confefernce, Phoenix, AZ, 2010, 1070-1076.

[9] Liu, B.Y.H. and Jordan, R. (1960) Interrelationships and Characteristic Distribution of Direct, Diffuse and Total Solar Radiation. Solar Energy, 4, 1-19. https://doi.org/10.1016/0038-092X(60)90062-1

[10] Marrodán, J. (2012) Piranómetro Fotovoltaico. Titulación: Ingeniero Técnico Industrial Eléctrico, Escuela Técnica Superior de Ingenieros Industriales y de Telecomunicación, Pamplona, España. 
http://www.academica-e.unavarra.es/bitstream/handle/2454/4670/577682.pdf

[11] Mendoza, I. and Piedra, D. (2006) Validación y ajuste de modelos de radiación solar directa para la ciudad de Bogotá a partir de datos experimentales. Revista Colombiana de Fisica, 38.

[12] Sánchez, C., Piedra, D. and Mendoza, I. (2006) Validación y ajuste de modelos de radiación solar directa para la ciudad de Bogotá a partir de datos experimentales tomados en la Universidad Distrital Francisco José de Caldas. Revista Colombiana de Física, 38, 1435-1438.

[13] Stanhill, G. (1998) Estimation of Direct Solar Beam Irradiance from Measurements of the Duration of Bright Sunshine. International Journal of Climatology, 18, 347-354. https://doi.org/10.1002/(SICI)1097-0088(19980315)18:3<347::AID-JOC239>3.0.CO; $\underline{2-\mathrm{O}}$

[14] Álvarez, O., Montaño, T. and Maldonado, J. (2014) La radiación solar global en la provincia de Loja, evaluación preliminar utilizando el método de Hottel. Ingenius, No. 11, 25.

[15] Molina, D., Álvarez, O. and Montaño, Th. (Inédito) Softwares para el cálculo de la radiación solar teórica con cielo despejado.

[16] Álvarez, O., Montaño, T., Quentin, E., Maldonado, J. and Solano, J.C. (2014) La radiación solar global en las provincias El Oro, Loja y Zamora Chinchipe, Ecuador. Utilización de datos de reanálisis de la nubosidad diurna. Revista de Climatología, 14, 25-33.

[17] USGS. SRTM. Geological Service of the United States.

[18] http://antongerdelan.net/opengl/kernels.html

[19] Consejo Nacional de Electricidad (CONELEC) and Corporación para la Investigación Energética (CIE) (2008) Atlas Solar del Ecuador con fines de Generación Eléctrica. Lugar de edición: Registro Instituto Ecuatoriano de Propiedad Intelectual: No. 028462 del 12 de marzo de 2008, No. 028369 del 26 de febrero de 2008, No. 028370 del 26 de febrero de 2008 editorial, 2008. Quito, Agosto 2008, 51. 